\title{
Influence of Temperature on Calcium Hydroxyapatite Nanopowders
}

\author{
Antonio Zanotto ${ }^{1 *}$, Maria Luisa Saladino ${ }^{2}$, Delia Chillura Martino ${ }^{2}$, Eugenio Caponetti ${ }^{1,2}$ \\ ${ }^{1}$ Centro Grandi Apparecchiature-UniNetLab, Università degli Studi di Palermo, Palermo, Italy \\ ${ }^{2}$ Dipartimento di Chimica "S. Cannizzaro", Università degli Studi di Palermo, Palermo, Italy \\ Email: "antonio.zanotto@unipa.it
}

Received September 5, 2012; revised October 8, 2012; accepted October 24, 2012

\begin{abstract}
The aim of this work is to investigate the effects of thermal treatment, in the range of temperature between $80^{\circ} \mathrm{C}$ $900^{\circ} \mathrm{C}$, on crystallinity, morphology and particles size of calcium hydroxylapatite nanopowders (HAp). A complete study was carried out applying ${ }^{31} \mathrm{P}$ Magic Angle Spinning NMR, X-ray diffraction, nitrogen porosimetry and Transmission Electron Microscopy techniques. HAp specimens were prepared by chemical precipitation in an aqueous solution of calcium nitrate and ammonium hydrogen phosphate. The thermal treatment performed, showed the formation of crystals whose appearance has three main morphologies and different particles size. HAp treated up to $500^{\circ} \mathrm{C}$ showed a set of needle-like shape crystals with a low surface area value. These crystals turned into rod-like crystals with temperature increase, along with an increase in crystallite size. At $900^{\circ} \mathrm{C}$ was detected a hexagonal hydroxylapatite phase. Furthermore, Dynamic Light Scattering explored a stable HAp dispersion. The isopropyl alcohol dispersion resulted stable for at least two weeks, useful to create layers of determined morphology nanoparticles.
\end{abstract}

Keywords: Hydroxylapatite; Precipitation; Thermal Treatment; Alcohol Dispersion

\section{Introduction}

In the recent years Calcium Hydroxyapatite, $\left(\mathrm{Ca}_{10}\left(\mathrm{PO}_{4}\right)_{6}\right.$ $(\mathrm{OH})_{2}$ ) has received much attention for its wide set of application: catalysis, fertilizers and pharmaceutics, protein chromatography and preparation of biocompatible materials such as artificial bones and teeth [1]. HA nanopowders (HAp) are mainly used as the source material to form sintered body and polymer composites $[2,3]$. Each application depends on HAp structure, crystallinity, particles size, and morphology. The growing interest of the scientific community on the HAp synthesis resulted in several chemical routes of investigation such as precipitation, sol-gel, microemulsion, synthesis assisted by microwave irradiation [4] or hydrothermal method, reverse micelle template system [5-10]. The three main difficulties arising at this phase are formation of nonstoichiometric products [1], low crystallinity due to experimental conditions such as $\mathrm{pH}$ and temperature and contamination of the used reactants, whose ions, sodium, potassium, nitrate and chloride, show strong affinity with HAp.

The thermal treatment influences the crystallinity, the mechanical properties and the catalytic activity. Only few

*Corresponding author. authors have systematically investigated the effects of temperature on the HAp crystallinity and crystals morphology. Pang and Bao [11] gave evidence of an increase of crystallinity and crystallite size due to the higher synthetic temperature and the ripening time. However the effect of calcination temperature on the obtained HAp was not taken into consideration.

This paper studies the effect of thermal treatment on samples obtained by precipitation, in particular its influence on the HAp crystallinity, morphology and particle size.

The characterization of the specimens was performed using ${ }^{31} \mathrm{P}$ Magic Angle Spinning NMR, X-ray diffraction (XRD), nitrogen porosimetry, and Transmission Electron Microscopy (TEM). In conclusion, the HAp samples were dispersed in liquid suspension, water and isopropyl alcohol, and tested using Dynamic Light Scattering (DLS), in order to monitor their behavior for some application such as catalysis and chromatography.

\section{Material and Methods}

\subsection{Materials}

$\mathrm{Ca}\left(\mathrm{NO}_{3}\right)_{2} \cdot 4 \mathrm{H}_{2} \mathrm{O}$ (Aldrich), $\left(\mathrm{NH}_{4}\right)_{2} \mathrm{HPO}_{4}$ (Aldrich) and ammonia solution (Aldrich 25\%) were used as received. Electrical resistivity of the used water was $18.1 \mathrm{M}$ ob- 
tained by a Culligan Pharma System.

\subsection{HAp Preparation}

The synthesis of HAp was obtained by precipitation method according to the following reaction [12]:

$$
\begin{aligned}
& 10 \mathrm{Ca}\left(\mathrm{NO}_{3}\right)_{2} \cdot 4 \mathrm{H}_{2} \mathrm{O}+6\left(\mathrm{NH}_{4}\right)_{2} \mathrm{HPO}_{4} \\
+ & 6 \mathrm{NH}_{4} \mathrm{OH}+2 \mathrm{NH}_{3} \rightarrow \mathrm{Ca}_{10}\left(\mathrm{PO}_{4}\right)_{6}(\mathrm{OH})_{2} \\
+ & 20 \mathrm{NH}_{4} \mathrm{NO}_{3}+10 \mathrm{H}_{2} \mathrm{O}
\end{aligned}
$$

In order to avoid the risk of contamination, a 7.14 M ammonia solution, maintained at $80^{\circ} \mathrm{C}$ to prevent the carbonation, was drop-wise added into a $1 \mathrm{M} \mathrm{Ca}\left(\mathrm{NO}_{3}\right)_{2}$ water solution to reach a $\mathrm{pH}$ value equal to 11 . When a 0.6 $\mathrm{M}\left(\mathrm{NH}_{4}\right)_{2} \mathrm{HPO}_{4}$ water solution was drop-wise added a white precipitate occurred. The stirred solution was first maintained at $80^{\circ} \mathrm{C}$ for $1 \mathrm{~h}$, and then at $37^{\circ} \mathrm{C}$ for $24 \mathrm{~h}$. The obtained precipitate was under vacuum filtered on Millipore membrane $(0.1 \mu \mathrm{m}, \mathrm{VCTP})$ and washed several times with water to remove residues of ammonia and nitrate ions, whose presence was qualitatively detected by using respectively concentrated hydrochloric acid and the brown ring test. Then, the sample was dried at $50^{\circ} \mathrm{C}$ in a vacuum oven.

Six aliquots of the obtained powder were treated at different temperatures $\left(150^{\circ} \mathrm{C}, 300^{\circ} \mathrm{C}, 500^{\circ} \mathrm{C}, 700^{\circ} \mathrm{C}\right.$ and $900^{\circ} \mathrm{C}$ ) for 1 hour.

\subsection{Characterization Techniques}

Transmission Electron Microscopy micrographs were acquired by using a JEM-2100 (JEOL, Japan) operating at $200 \mathrm{kV}$ accelerating voltage. A HAp aliquot was dispersed in isopropanol and ultrasound treated for $20 \mathrm{~min}$ to ensure a homogeneous dispersion. A small drop was deposited on a 400 mesh carbon-coated copper grid, which was introduced into the TEM chamber analysis after the complete solvent evaporation.

X-ray diffraction patterns were recorded at room temperature with a Philips PW 1050/39 diffractometer in the Bragg-Brentano geometry using a $\mathrm{Ni}$ filtered $\mathrm{Cu} \mathrm{K} \alpha$ radiation $(\lambda=1.54056 \AA)$. The $\mathrm{X}$-ray generator worked at a power of $40 \mathrm{kV}$ and a current of $30 \mathrm{~mA}$. The instrument resolution (divergent and antiscatter slits of $0.5^{\circ}$ ) was determined using standards free from the effects of reduced crystallite size and lattice defects. Powder patterns were analysed according to the Rietveld method [13] using the MAUD software [14].

Nitrogen absorption-desorption isotherms were Registered at $77 \mathrm{~K}$ using a Quantachrome Nova 2200 MultiStation High Speed Gas Sorption Analyser. Samples were outgassed for $3 \mathrm{~h}$ at room temperature in the degas station. Adsorbed nitrogen volumes were normalized to standard temperature and pressure. The specific surface area $\left(\mathrm{S}_{\mathrm{BET}}\right)$ was calculated according to the standard $\mathrm{BET}$ method [15] in the relative absorption pressure $\left(\mathrm{P} / \mathrm{P}_{0}\right)$ range from 0.045 to 0.250 .

${ }^{31} \mathrm{P}$ Magic Angle Spinning Nuclear Magnetic Resonance (31P MAS NMR) spectra were obtained at room temperature through a Bruker Avance II $400 \mathrm{MHz}(9.4 \mathrm{~T})$ spectrometer operating at $161.98 \mathrm{MHz}$ for the ${ }^{31} \mathrm{P} \mathrm{nu}-$ cleus with a MAS rate of $5 \mathrm{kHz}, 32$ scans, a repetition delay of $8 \mathrm{sec}$ and a pulse length of $6.25 \mu \mathrm{s} .10 \mathrm{mg}$ of each sample were placed in a $4 \mathrm{~mm}$ zirconia rotor with KEL-F cap. The chemical shifts were referred to an $85 \%$ solution of phosphoric acid $\left(\mathrm{H}_{3} \mathrm{PO}_{4}\right)$, external standard.

Dynamic Light Scattering measurements were carried out by using a Brookhaven Instrument equipped with a BI-9000AT Digital Autocorrelator. The light source was a He-Ne $632.8 \mathrm{~nm}$ laser working at a power of $75 \mathrm{~mW}$. The detector was a photomultiplier tube. The source and the detector were mounted on a turntable and the measurements were performed at $90 \AA$. Data were acquired for $5 \mathrm{~min}$ and were directly obtained as electric field self-correlation function, $\mathrm{g}(\tau)$, versus the decay time, $\tau$, by using the software supplied by Brookhaven Inc..

\section{Results and Discussion}

\subsection{Powder Characterization}

In order to evaluate the particle size and morphology, a TEM investigation was performed. Some TEM micrographs are reported in Figure 1.

A TEM data summary including shape and size of the particles is reported in Table 1.

Some aggregate of needle-shape particles randomly oriented were detected in the as-prepared sample and in the samples treated at $150^{\circ} \mathrm{C}$ and $300^{\circ} \mathrm{C}$. Samples treated at $500^{\circ} \mathrm{C}$ and at $700^{\circ} \mathrm{C}$ are constituted by aggregated rod-like particles. This aggregation was attributed to Van der Waals interaction by Martin et al. [16]. The morphology of the HAp treated at $900^{\circ} \mathrm{C}$ is different from the others. Two different particle morphologies are observed, the first one has an irregular rod-like shape and size around $56 \mathrm{~nm}$ width and $220 \mathrm{~nm}$ length. The second one has a hexagonal-like shape and sizes around $65 \mathrm{~nm}$ width and $\sim 80 \mathrm{~nm}$ length.

The possible nano-needle nucleation and growth to the consecutive nano-rod and hexagonal transformation could be attributed to the relative specific surface energies, which determine the $\mathrm{OH}$-quantity, associated with the different facets of HA crystal [17]. The particles morphology changes in uniaxial direction (facets with less $\mathrm{OH}$-concentration) on increasing the temperature. Nevertheless this phenomenon is not clear yet, further theoretic studies will be needed to deeply understand the complex growth mechanism. 

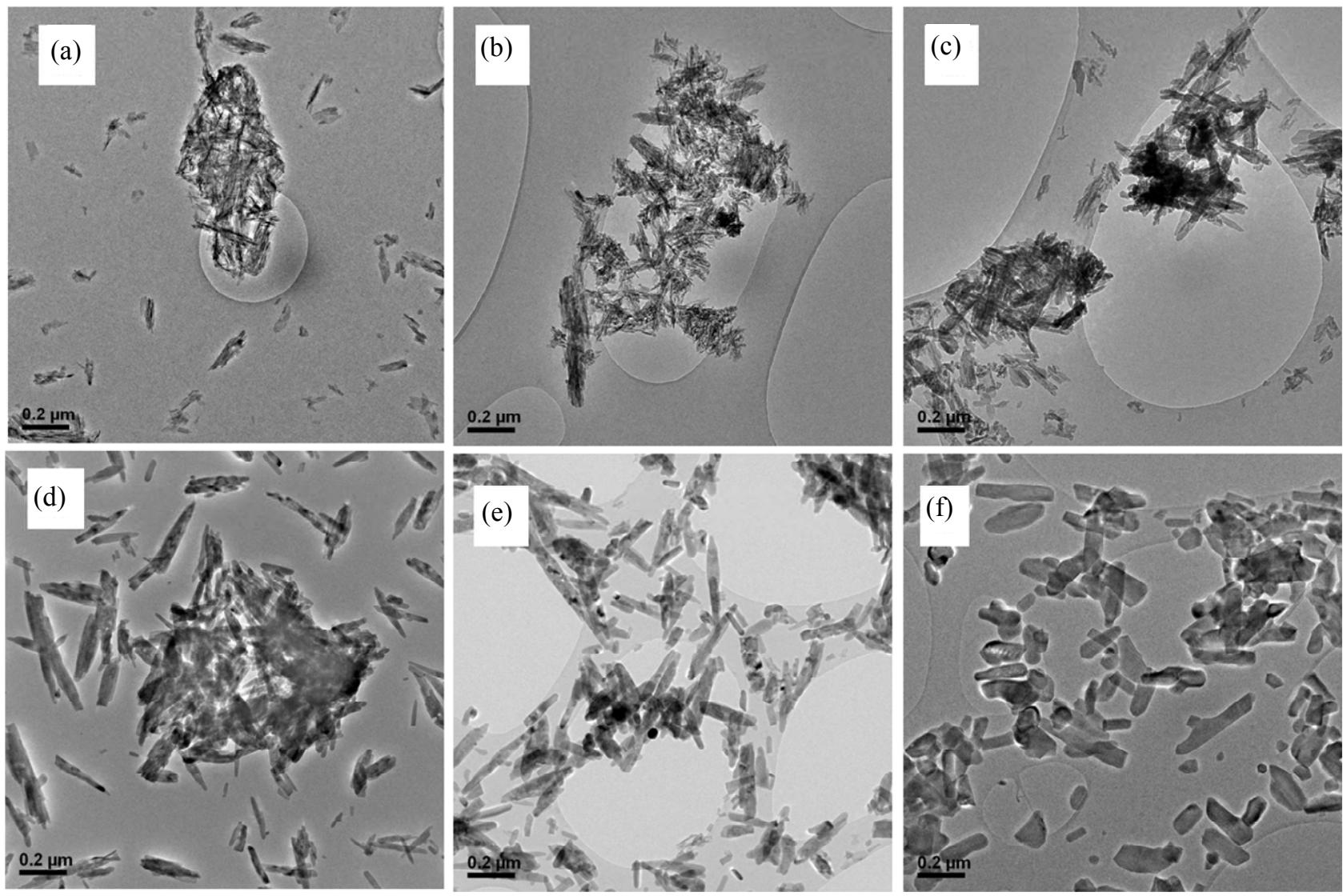

Figure 1. TEM micrographs of the (a) as-prepared $\mathrm{HA}$ and of samples treated at (b) 150, (c) 300, (d) 500, (e) 700 , (f) $900^{\circ} \mathrm{C}$.

Table 1. TEM data summary.

\begin{tabular}{cccc}
\hline sample & Shape & Width $(\mathrm{nm})$ & Length (nm) \\
\hline as-prepared & needle & 4 & $\sim 70$ \\
150 & needle & 5 & $\sim 85$ \\
300 & needle & 23 & $\sim 120$ \\
500 & rod & 22 & $\sim 225$ \\
700 & rod & 34 & $\sim 123$ \\
900 & rod-hexagonal & $56-65$ & $\sim 220-\sim 80$ \\
\hline
\end{tabular}

The investigation of crystalline structure was carried out by XRD technique. Diffraction patterns of all HAp samples treated at different temperature, are shown in Figure 2. The bar sequence of the hexagonal hydroxylapatite diffraction pattern is shown at the bottom, as reference. The residues of sample treated at $900^{\circ} \mathrm{C}$, that obtained the best Rietveld fit, are reported at the top. The agreement between computed and experimental data is fairly good in every pattern.

The pattern of the as-prepared sample is reproduced by the hexagonal structure (space group P63/m, lattice pa- rameters $\mathrm{a}=\mathrm{b}=9.430, \mathrm{c}=6.891 \AA, \alpha=\beta=90^{\circ}, \gamma=$ $120^{\circ}$ ). The absence of the characteristic peaks, given by impurities or secondary phases, indicates that the HA highly pure crystalline phase has formed at $80^{\circ} \mathrm{C}$. However, the peak profile is very broad thus accounting for both the nanocrystalline condition of materials and lattice large disorder. The mean particle size, D, and the lattice disorder, $\varepsilon$, resulted, respectively $316(2) \AA$, and $1.5 \times$ $10^{-3}$.

The XRD patterns of the aliquots treated at $150,300,500$, 700 , and $900^{\circ} \mathrm{C}$ were also described by the hexagonal HA 


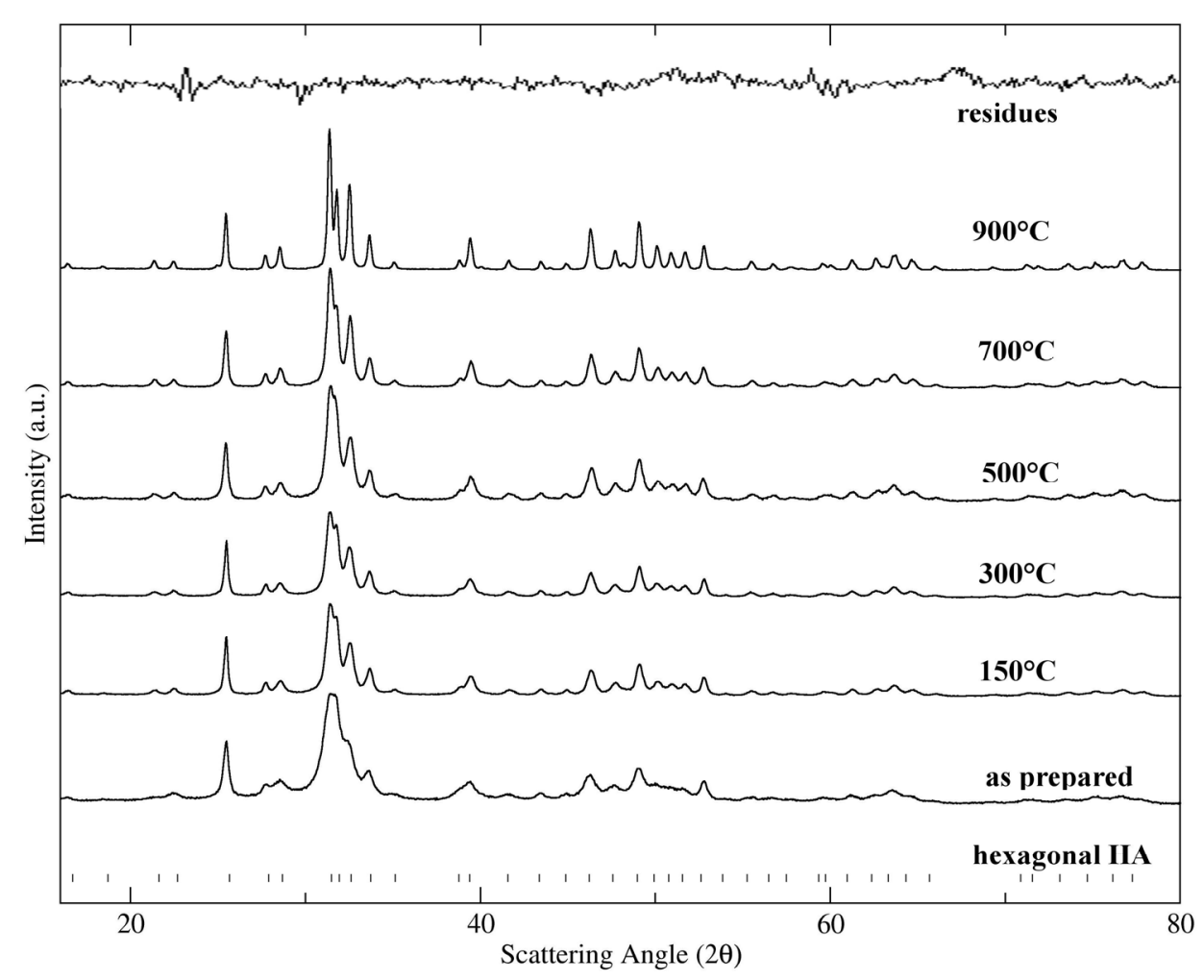

Figure 2. XRD patterns (dots) and Rietveld fits (full lines) of the HAp samples treated at different temperature. The bar sequence of reference diffraction pattern and a curve of residuals are shown along the bottom and top, respectively.

phase. The peak broadening of the HAp samples decreases on increasing the temperature, indicating that the crystallinity increases. The cell parameters $\mathrm{a}, \mathrm{b}$ and $\mathrm{c}$, the average crystallite size, $\mathrm{D}$, and the lattice disorder, $\varepsilon$, calculated using the Rietveld method [13], are reported in Table 2. The lattice parameters and the related cell volume of the HA phase do not appreciably change with the treatment temperature. The average crystallite size, D, corresponding to the average coherent diffraction domain, was calculated after separating strain from size effects according to the Rietveld approach [13] using the isotropic model, which can be regarded as a first approximation for a volume weighted average size of crystallites, regardless their shape and texture. It is known that the assumption of isotropic size and strain may be questionable when dealing with HA-materials. In particular, the (002) peak at $\mathrm{d}=3.44\left(2 \theta=25.85^{\circ}\right)$ appears sharper than the others. This confirms the existence of texture along this direction [18]. Nevertheless, this approach can be used to estimate the influence of temperature. In order to visualize this effect, the increase of the average crystallite size of the HAp phase is reported in Figure 3(a) as function of temperature.

In the temperature range $80^{\circ} \mathrm{C}-500^{\circ} \mathrm{C}$ the growth rate is about $7 \AA /{ }^{\circ} \mathrm{C}$. Around $500^{\circ} \mathrm{C}$ the $\mathrm{D}$ value suddenly increases thus confirming that high temperature is necessary to obtain bigger and more ordered crystals. This result is further confirmed by the lattice disorder parameter, whose value slightly decreases as expected after an initial increase that accounts for the displacement and the broadening of diffraction peaks. The fraction of crystalline phase (Xc) was evaluated according to the literature approach reported by Pang and Bao [11] by means of the following equation:

$$
\mathrm{Xc}=1-\left(\mathrm{V}_{112 / 300} / \mathrm{I}_{300}\right)
$$

where $I_{300}$ is the intensity of the (300) diffraction peak and $V_{112 / 300}$ is the intensity of the hollow between (112) and (300) diffraction peaks. Values are reported in Table 2.

The Xc value increases from 0.28 to 0.99 indicating a strong temperature dependence of the crystallinity, as shown in Figure 3(b).

The trend of Xc differs from the dependence law of D. This indicates that the temperature sensitivity of the crystallinity is higher than the one of the crystalline domain sizes. These results suggest that the HA nanocrystals are poorly organized to form bigger structure, but their organization and regularity improve on increasing the temperature according to the TEM results.

The knowledge about the surface area could give some basic informations on catalysis. For this reason the nitrogen adsorption-desorption isotherms were carried out. 
Table 2. Cell parameters a, b and c, average crystallite size (D), lattice disorder ( $(\varepsilon)$ of the HA phase and fraction of crystalline phase (Xc).

\begin{tabular}{|c|c|c|c|c|c|}
\hline sample & $\mathrm{a}=\mathrm{b}(\AA \hat{\AA})$ & $\mathrm{c}(\hat{\AA})$ & $\mathrm{D}(\AA \hat{)})$ & $\varepsilon \cdot 10^{-3}$ & $\mathrm{Xc}$ \\
\hline as-prepared & $9.433(2)$ & $6.891(1)$ & $232(1)$ & $1.5(1)$ & 0.28 \\
\hline 300 & $9.425(1)$ & $6.889(2)$ & $255(2)$ & $1.8(2)$ & 0.33 \\
\hline 500 & $9.416(3)$ & $6.896(2)$ & $268(3)$ & $1.4(1)$ & 0.49 \\
\hline 700 & $9.417(2)$ & $6.892(4)$ & $384(1)$ & $1.5(1)$ & 0.83 \\
\hline 900 & $9.419(2)$ & $6.885(2)$ & $813(8)$ & $0.5(1)$ & 0.99 \\
\hline
\end{tabular}

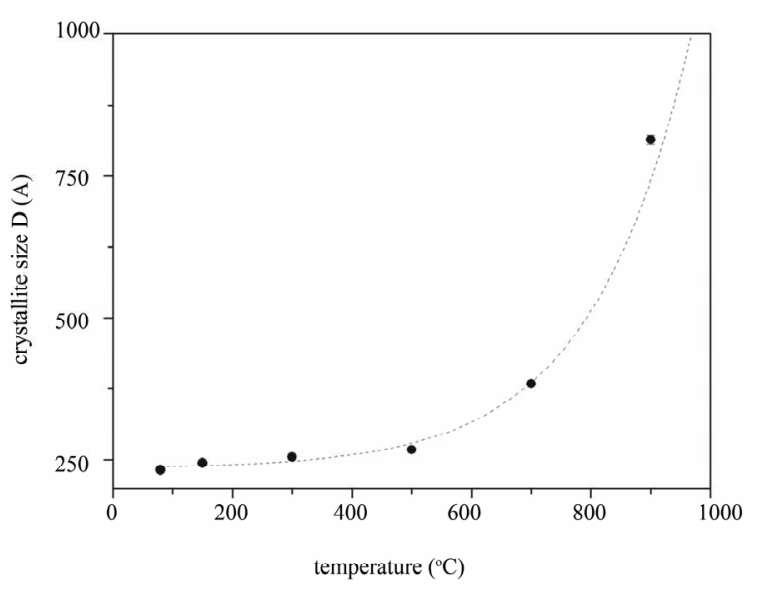

(a)

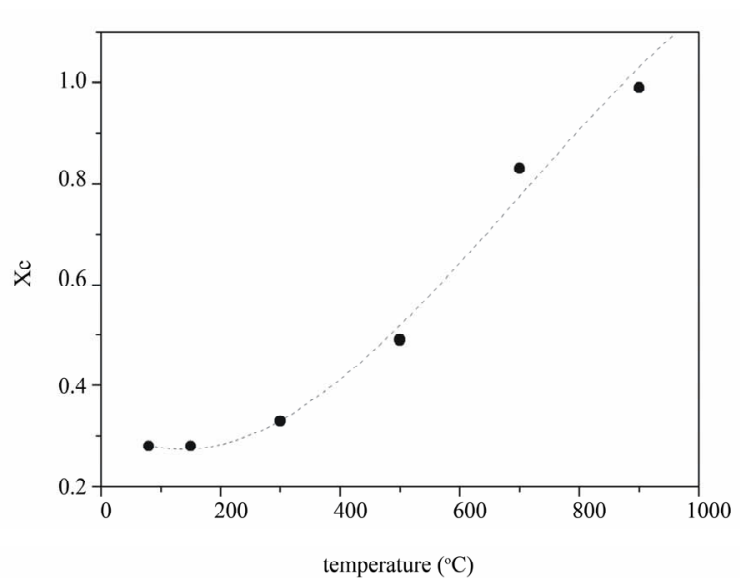

(b)

Figure 3. (a) Average crystallite size, D, of the HA phase as function of temperature and (b) fraction of crystalline phase Xc (the dashed line are a guide for eyes).

The profile of isotherms of all samples treated up $900^{\circ} \mathrm{C}$ are similar. An example of, N2 adsorption and desorption isotherms of HAp samples treated at 150,700 and $900^{\circ} \mathrm{C}$ are reported in Figure 4(a).

All isotherms show a slow increase in the adsorbed amount of $\mathrm{N}_{2}$. According to the IUPAC classification, the observed N2 adsorption isotherms can be identified as type III with an H1 type hysteresis loop [19], characterized by a low surface area. When the relative pressure increases, multilayer absorption occurs until all empty spaces are filled up. The obtained BET specific surface area $\left(\mathrm{S}_{\mathrm{BET}}\right)$, calculated in the $0.045-0.250$ relative pressure range, are reported as function of the temperature in Figure 4(b). The $\mathrm{S}_{\mathrm{BET}}$ value decreases with temperature. This result is consistent with the particle size increase, even if after $500^{\circ} \mathrm{C}$ the more rapid surface area decrease could be attributed to the variation of crystal morphology.

The ${ }^{31} \mathrm{P}$ MAS NMR spectra were acquired on all samples. As an example, ${ }^{31} \mathrm{P}$ MAS NMR spectra of HAp samples treated at 150 and $900^{\circ} \mathrm{C}$ are compared in Figure 5.
The spectrum of the sample treated at $150^{\circ} \mathrm{C}$ (lower spectrum in Figure 5) shows the typical HA peak at 2.5 ppm together with an additional broad foot. It indicates the presence of nanoscopic particles with a low degree of crystallinity [20]. The corresponding peak of the sample treated at $900^{\circ} \mathrm{C}$ (upper spectrum in Figure 1) differs from the previous in narrow line-width and for the absence of the broad foot indicating an increase of particles size and crystallinity.

\subsection{Dispersion Characterization}

The possibility to obtain stable dispersion of nanosized crystals is useful in some applications such as catalysis or chromatography. Since some authors have reported the role of isopropanol to obtain a stable dispersion $[21,22]$, the HAp were dispersed both in water and in isopropanol $(0,01 \mathrm{M})$ in order to obtain information about their behaviour.

A fast precipitation occurs in all samples dispersed in water, while particles dispersed in isopropanol are well maintained in suspension. The DLS investigation was carried out on the powder dispersed in isopropanol. DLS 


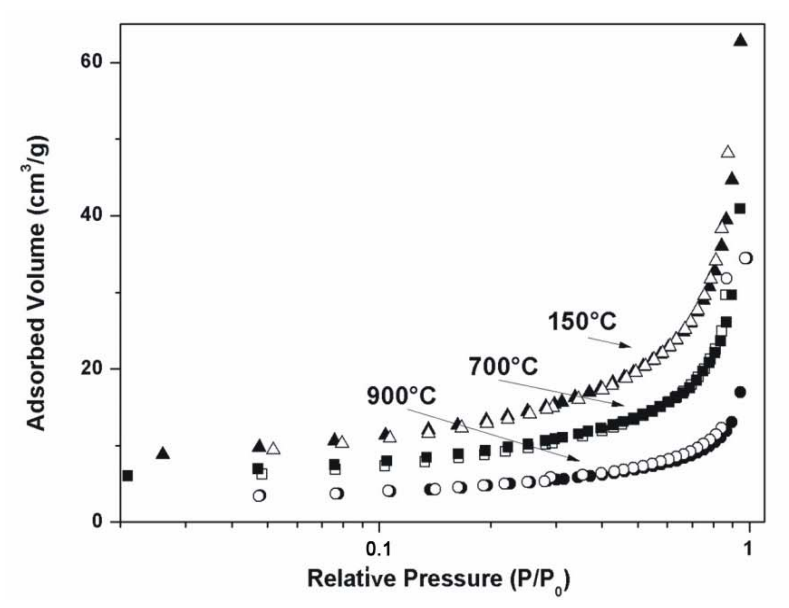

(a)

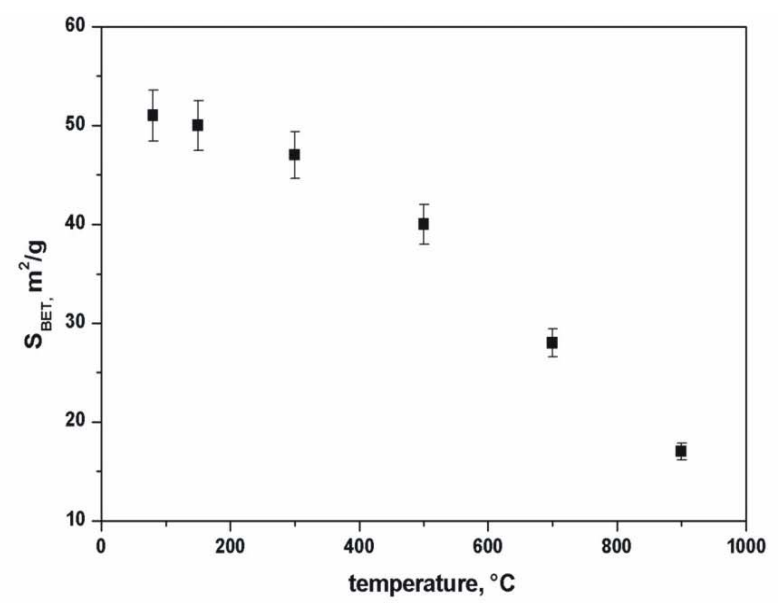

(b)

Figure 4. (a) $\mathrm{N}_{2}$ adsorption isotherms of samples treated at 150,700 and $900 \mathrm{C}$; (b) $\mathrm{S}_{\mathrm{BET}}$ of the $\mathrm{HAp}$ samples as function of temperature.

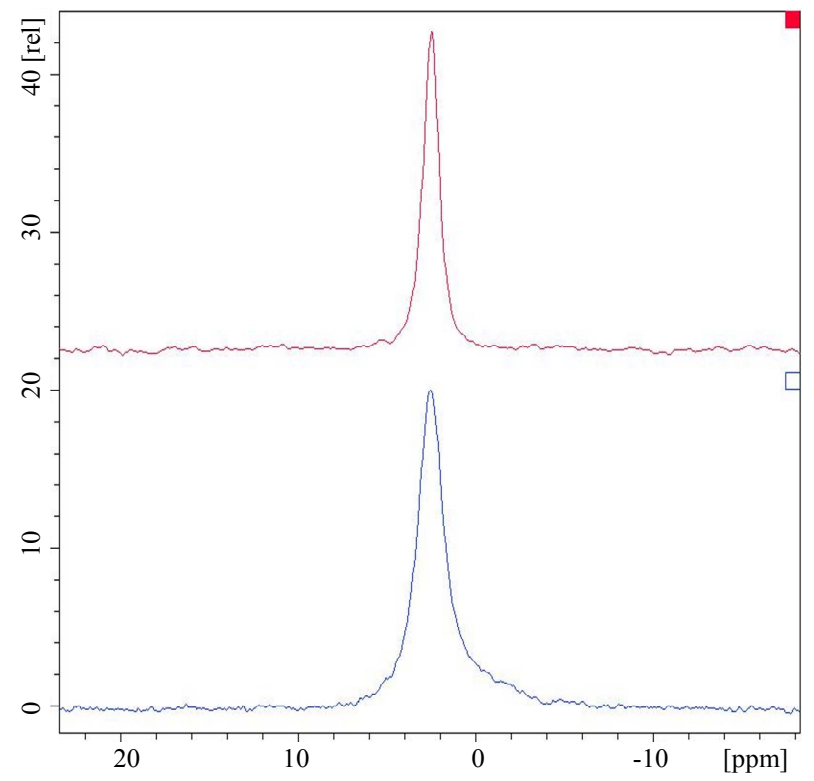

Figure 5. ${ }^{31} \mathrm{P}$ MAS NMR spectra of the HAp treated at $150^{\circ} \mathrm{C}$ (lower spectrum) and at $900^{\circ} \mathrm{C}$ (upper spectrum).

data had a good statistic and reproducibility. An example of, the un-normalized electric field self-correlation function $\mathrm{C}(\tau)$ as a function of the decay time, $\tau$, of the as-prepared HAp dispersed in isopropanol is reported in Figure 6(a).

Data indicate that the signal is self-correlated up to 0.5 msec and the correlation is completely lost around 50 msec, thus, indicating that the diffusing unity have large size. The self-correlation function computed using the Cumulant analysis [23] did not satisfactorily reproduce the experimental data suggesting that the particles in suspension are polydisperse. A more appropriate data analysis related to a polydisperse sample model was done using the CONTIN method [24]. The computed self- correlation function, reported as a continuous line in the Figure 6(a), well reproduced the experimental data. The histogram of particle size distribution, evaluated by applying this approach, is reported in the inset of the Figure 6(a). The mean hydrodynamic diameter value is 571 $\mathrm{nm}$. This value is strongly higher than the ones by TEM and XRD. This finding can not be explained by considering the solvation sphere of each particle. It suggests the formation of agglomerates in suspension.

The same approach of data analysis was used for all the other samples. The trend of the mean size as function of temperature is reported in Figure 6(b). The mean value lies in the range of 571 to $2870 \mathrm{~nm}$ and increases with the temperature according to results obtained by other techniques.

The measurements have been repeated two weeks later. The obtained mean particle size was in the same range indicating that the dispersion was stable over that period of time.

Considering that the stability of a dispersion is the results of a delicate balance of attractive and repulsive forces, it appears that in the samples treated at higher temperature the solvent causes the coalescence of particles making bigger aggregates which cause surface free energy minimization: the repulsive forces were screened thus promoting the coalescence and hence the formation of big, polydispersed aggregates. This mechanism more likely occurs in water than in isopropanol because of the relative strength of hydrogen's bonds causing the building of super-aggregates which precipitate immediately in the dispersion.

\section{Conclusions}

The HA nanopowders were prepared by precipitation and were systematically investigated as a function of temperature from $80^{\circ} \mathrm{C}$ up to $900^{\circ} \mathrm{C}$. High purity HAp are 


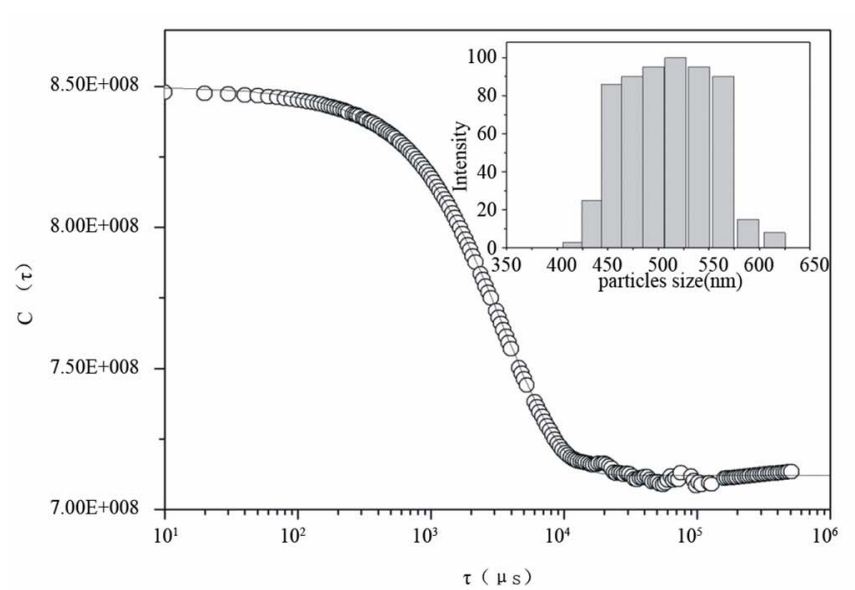

(a)

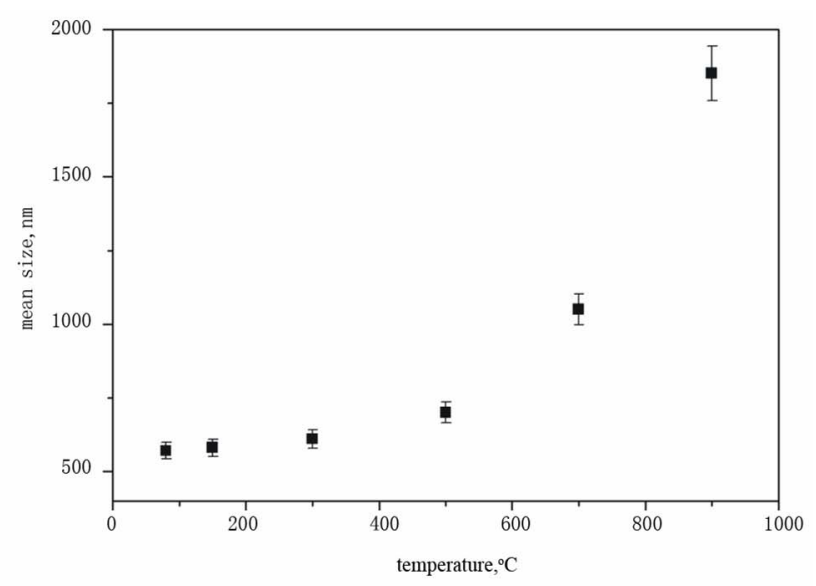

(b)

Figure 6. (a) The correlation function $\mathrm{C}(\tau)$ of as-prepared HAp dispersed in isopropanol. The solid line represents the best fit obtained using the CONTIN method [22]. In the inset the histogram of particles distribution. (b) Mean dimension of HA aggregates as function of temperature.

obtained at low temperature and HA structure is maintained up to $900^{\circ} \mathrm{C}$. The HAp with lower crystallinity show needle-like shape particles with a low surface area value, whereas the HAp with higher crystallinity have rod shape particles. The increase in crystalline size with tempera- ture takes place by the growth of the particles in uniaxial direction (facets with less $\mathrm{OH}$-concentration).

The use of isopropanol to obtain a stable HAp dispersion was successfully demonstrated. The stabilization was attributed to relative surface energies of HAp facets, to the balance of attractive and repulsive forces and to the relative strength of hydrogen's bonds of the medium. Furthermore, the stability of dispersion could allow to create nanoparticles layers with determined surface.

\section{Acknowledgements}

The authors would like to thank MIUR for supporting this research through the PRIN 2009 prot. 2009WXXLY2_004 "Application of microwaves irradiation on some inorganic syntheses and on bioactive compound and essential oils extraction". ${ }^{31} \mathrm{P}$ MAS NMR, and TEM experimental data were provided by Centro Grandi ApparecchiatureUniNetLab-Universita' di Palermo funded by P.O.R. Sicilia 2000-2006, Misura 3.15 Azione C Quota Regionale. A.Z. acknowledges the MIUR and INSTM fellowship for his work on "TEM analysis on nanostructured composites", and Dr. Oriana Giovanna Guarino.

\section{REFERENCES}

[1] S. Koutsopoulos, "Synthesis and Characterization of Hydroxyapatite Crystals: A Review Study on the Analytical Methods," Journal of Biomedical Materials Research Part A, Vol. 62, No. 4, 2002, pp. 600-612.

[2] W. W. Thein-Han and R. D. K. Misra, "Biomimetic Chi-
tosan-Nanohydroxyapatite Composite Scaffolds for Bone Tissue Engineering," Acta Biomaterialia, Vol. 5, No. 4, 2009, pp. 1182-1197. doi:10.1016/j.actbio.2008.11.025

[3] C. Tsioptsias, I. Tsivintzelis, L. Papadopoulou and C. Panayiotou, "A Novel Method for Producing Tissue Engineering Scaffolds from Chitin, Chitin-Hydroxyapatite, and Cellulose," Materials Science and Engineering $C$, Vol. 29, No. 1, 2009, pp. 159-164.

[4] Y. Torrent-Burgués, J. Gómez-Morales, A. López-Macipe, and Y. A. Rodríguez-Clemente, "Continuous Precipitation of Hydroxyapatite from $\mathrm{Ca} / \mathrm{Citrate} / \mathrm{Phosphate} \mathrm{Solu-}$ tions Using Microwave Heating," Crystal Research and Technology, Vol. 34, No. 5-6, 1999, pp. 757-762.

[5] M. H. Fathi and A. Hanifi, "Evaluation and Characterization of Nanostructure Hydroxyapatite Powder Prepared by Simple Sol-Gel Method," Materials Letters, Vol. 61, No. 8, 2007, pp. 3978-3983.

[6] Z. H. Zhou, P. L. Zhou, S. P. Yang, X. B. Yu and L. Z. Yang, "Controllable Synthesis of Hydroxyapatite Nanocrystals via a Dendrimer-Assisted Hydrothermal Process," Yang, Materials Research Bulletin, Vol. 42, No. 9, 2007, pp. 1611-1618.

[7] X. Zhang and K. S. Vecchio, "Hydrothermal Synthesis of Hydroxyapatite Rods," Journal of Crystal Growth, Vol. 308, No. 1, 2007, pp. 133-140.

[8] S. Kannan, J. H. G. Rocha, S. Agathopoulos and J. M. F. Ferreira, "Fluorine-Substituted Hydroxyapatite Scaffolds Hydrothermally Grown from Aragonitic Cuttlefish Bones," Acta Biomaterialia, Vol. 3, No. 2, 2007, pp. 243-249. doi:10.1016/j.actbio.2006.09.006

[9] A. Wang, D. Liu, H. Yin, H. Wu, Y. Wada, M. Ren, T. Jiang, X. Cheng and Y. Xu, "Size-Controlled Synthesis of Hydroxyapatite Nanorods by Chemical Precipitation in the Presence of Organic Modifiers," Materials Science and Engineering: $C$, Vol. 27, No. 4, 2007, pp. 865-869.

[10] A. Banerjee, A. Bandyopadhyay and S. Bose, "Hydroxyapatite Nanopowders: Synthesis, Densification and CellMaterials Interaction," Materials Science and Engineer- 
ing: C, Vol. 27, No. 4, 2007, pp. 729-735.

[11] Y. X. Pang and X. Bao, "Influence of Temperature, Ripening Time and Calcination on the Morphology and Crystallinity of Hydroxyapatite Nanoparticles," Journal of the European Ceramic Society, Vol. 23, No. 10, 2003. pp. 1697-1704.

[12] H. Yu, H. Zhang, X. Wang, Z. Gu, X. Li and F. Deng, "Local Structure of Hydroxy-Peroxy Apatite: A Combined XRD, FT-IR, Raman, SEM, and Solid-State NMR Study," Journal of Physics and Chemistry of Solids, Vol. 68, No. 10, 2007, pp. 1863-1871.

[13] R. A. Young, "The Rietveld Method," University Press, Oxford, 1993.

[14] L. Lutterotti and S. Gialanella, "X-Ray Diffraction Characterization of Heavily Deformed Metallic Specimens," Acta Materialia, Vol. 46, No. 1, 1998, pp. 101-110.

[15] S. Brunauer, P. H. Emmett and E. Teller, "Adsorption of Gases in Multimolecular Layers," Journal of the American Chemical Society, Vol. 60, No. 2, 1938, pp. 309-319.

[16] C. L. Martin, G. Delette and D. Bouvard, "Discrete Element Simulations of the Compaction of Aggregated Ceramic Powders," Journal of the American Chemical Society, Vol 89, No. 11, 2006, pp. 3379-3387.

[17] K. P. Sanosh, M. C. Chu, A. Balakrishnan, Y. J. Lee, T. N. Kim and S. J. Cho, "Synthesis of Nano Hydroxyapatite Powder That Simulate Teeth Particle Morphology and Composition," Current Applied Physics, Vol. 9, No. 6, 2009, pp.1459-1462.

[18] I. Zizak, O. Paris, P. Roschger, S. Bernstorff, H. Amenitsch, K. Klaushofer and P. Fratzl, "Investigation of Bone and
Cartilage By Synchrotron Scanning-SAXS and -WAXD with Micrometer Spatial Resolution," Journal of Applied Crystallography, Vol 33, No. 1, 2000, pp. 820-823. doi:10.1107/S0021889800001321

[19] IUPAC, "Manual of Symbols and Terminology, Appendix 2, Part 1, Colloid and Surface Chemistry," Pure and Applied Chemistry, Vol. 31, No. 4, 1972, pp. 578-638.

[20] C. Jäger, T. Welzel, W. Meyer-Zaika and M. Epple, “A Solid-State NMR Investigation of the Structure of Nanocrystalline Hydroxyapatite," Magnetic Resonance in Chemistry, Vol. 44, No. 6, 2006, pp. 573-580. doi: $10.1002 / \mathrm{mrc} .1774$

[21] A. Zanotto, R. Matassa, M. L. Saladino, M. Berrettoni, M. Giorgetti, S. Zamponi and E. Caponetti, "Cobalt Hexacyanoferrate-Poly(Methyl Methacrylate) Composite: Synthesis and Characterization," Materials Chemistry and Physics, Vol. 120, No. 1, 2010, pp. 118-122. doi:10.1016/j.matchemphys.2009.10.032

[22] E. Fratini, M. G. Page, R. Giorgi, H. Cölfen, P. Baglioni, B. Demé and T. Zembo, "Competitive Surface Adsorption of Solvent Molecules and Compactness of Agglomeration in Calcium Hydroxide," Nanoparticles Langmuir, Vol. 23, No. 5, 2007, pp. 2330-2338. doi:10.1021/la062023i

[23] D. E. Koppel, "Analysis of Macromolecular Polydispersity in Intensity Correlation Spectroscopy: The Method of Cumulants," Journal of Chemical Physics, Vol. 57, No. 11, 1972, pp. 4814-4821.

[24] B. J. Berne and R. Pecora, "Dynamic Light Scattering," Wiley, New York, 1976. 